\title{
INFLUENCE OF AGITATION AND AERATION ON XYLITOL PRODUCTION BY THE YEAST Starmerella meliponinorum
}

\author{
Rosimeire Oenning da Silva ${ }^{\mathrm{a}, *, \bullet}$, Meirielem do Nascimento Serpa $^{\mathrm{a}}$ and Fábio Cristiano Angonesi Brod ${ }^{\mathrm{a}}$ \\ aDepartamento de Engenharia de Alimentos, Faculdade de Arquitetura e Engenharia, Universidade do Estado do Mato Grosso, \\ 78390-000 Barra do Bugres - MT, Brasil
}

Recebido em 19/11/2019; aceito em 23/03/2020; publicado na web em 04/05/2020

\begin{abstract}
The production of xylitol from pentose-fermenting yeast is closely related to the amount of oxygen present in the culture medium. This study evaluated the effects of agitation and aeration in xylitol production using the yeast Starmerella meliponinorum FRP.09, previously isolated and selected due to its capacity to produce ethanol and xylitol from xylose. Fermentations were conducted in $125 \mathrm{~mL}$ flasks with $15 \mathrm{~mL}$ of culture medium and shaken at $150 \mathrm{rpm}$ and $200 \mathrm{rpm}$ without forced aeration and compared to fermentation in a static system. To assess the forced aeration, bioreactor was used with an air flow of $0.1 \mathrm{vvm}$ and agitation of $100 \mathrm{rpm}, 0.25 \mathrm{vvm} / 150 \mathrm{rpm}$ and $0.5 \mathrm{vvm} / 200 \mathrm{rpm}$. Higher agitation and airflow significantly increased the xylose consumption. The yeast S. meliponinorum FRP.09 achieved the best xylitol yield of $0.6 \mathrm{~g}$ of xylitol per $\mathrm{g}$ of xylose consumed, when the fermentation was conducted with an air flow/rotation speed of $0.5 \mathrm{vvm} / 200 \mathrm{rpm}$ in bioreactor and $150 \mathrm{rpm}$ in the fermentation flasks.
\end{abstract}

Keywords: yield of xylitol; xylose; fermentation; aeration.

\section{INTRODUCTION}

Xylitol is a polyol that has attracted the attention of researchers due to its unique properties that allow its use in several industrial sectors. Besides presenting anticariogenic properties, xylitol is used as a low-calorie sweetener and can be used by diabetics because it does not pass through the cycle of insulin in the human body. ${ }^{1}$ This molecule is widely distributed in nature but its low concentration in plants makes its extraction uneconomical. A commercial xylitol production process occurs by chemical catalysis of xylose from plant biomass. The solution of xylose is hydrogenated using nickel as a catalyst and xylitol is recovered by chromatographic fractionation using an ion exchange resin. ${ }^{2}$ This is a costly process due to the need for successive purification steps of the initial solution of xylose and also the final xylitol product. ${ }^{3}$ Thus, the microbial conversion of xylose to xylitol is a good alternative to the conventional commercial method.

This production can be achieved without the need for the initial purification of D-xylose. However, in order to make the process economically viable at the industrial scale, the conversion must provide a high yield and rate of production and the environmental conditions must be adjusted to the yeast's metabolic needs. In submerged fermentation, agitation is important for several reasons: to obtain a good homogenization preventing settling of the cells; to provide greater surface contact with the medium; and to ensure the transfer of oxygen from the gas phase (air) into the liquid phase (medium) where it will be consumed by microorganisms in respiration and other biochemical reactions.

In fermentation kinetics without aeration, oxygen is transferred from the space above the liquid by agitation that continuously breaks the liquid surface and increase the oxygen transfer. Without agitation, the access to oxygen by microorganisms is limited. It is important to remember that several types of reactions require oxygen as a reagent, such as sterol biosynthesis on yeast membranes. The production of lipids does not occur in the absence of oxygen, which affects the strength and stability of the plasma membrane. ${ }^{4}$ Moreover,

*e-mail: rosimeireoenning@gmail.com the production of xylitol from yeast pentoses is closely related to the amount of oxygen present in the medium. ${ }^{5}$

Xylitol can be produced in fermentation processes from xylose as long as there is a microorganism capable of fermenting this carbon source. However, only a few yeasts are described in the literature as fermenting xylose, and producing xylitol, such as: Debaryomyces hansenii, ${ }^{6}$ Candida parapsilopsis, ${ }^{7}$ Pichia capsulata, Pachysolen tannophilus, D. hansenii, ${ }^{8}$ C. guilliermondii, ${ }^{9}$ Candida tenuis. ${ }^{5}$ Among these, the high performance yielded by the strain Candida guilliermondii, one of the most studied yeasts for the production of xylitol which can achieve a yield (Y p/s) up to $0.90 \mathrm{~g} \mathrm{~g}^{-1}$, with productivity (Qp) of $0.50 \mathrm{~g} \mathrm{~L}^{-1} \mathrm{~h}^{-1} .{ }^{10}$ Figure 1 illustrates carbon metabolism from xylose to ethanol by yeast.

Until now, the xylose metabolism by the yeast Starmerella meliponinorum FRP.09 is not known. This strain was previously isolated and selected because of its ethanol and xylitol production capacity, but in order to evaluate its performance in xylose metabolism the culture conditions need to be established. To this end, the effects of agitation and aeration on the production of xylitol from xylose in a semisynthetic medium were evaluated. Agitation at 150 and $200 \mathrm{rpm}$ without forced aeration was evaluated and compared to fermentations in static and agitation systems (100, 150 and $200 \mathrm{rpm})$ with oxygen flows from compressed air $(0.1,0.25$ and $0.5 \mathrm{vvm})$.

\section{EXPERIMENTAL}

\section{Microorganisms}

S. meliponinorum FRP.09 was obtained from the Culture Collection of the Laboratory of Biochemistry and Applied Microbiology, São Paulo State University, Brazil. The yeast had previously been isolated from flowers collected in urban areas in São José do Rio Preto, SP, and it was selected for its xylose fermentation capacity.

\section{Culture medium for yeast growth}

YEPD medium: $2 \%$ peptone, $1 \%$ yeast extract, $2 \%$ dextrose, 


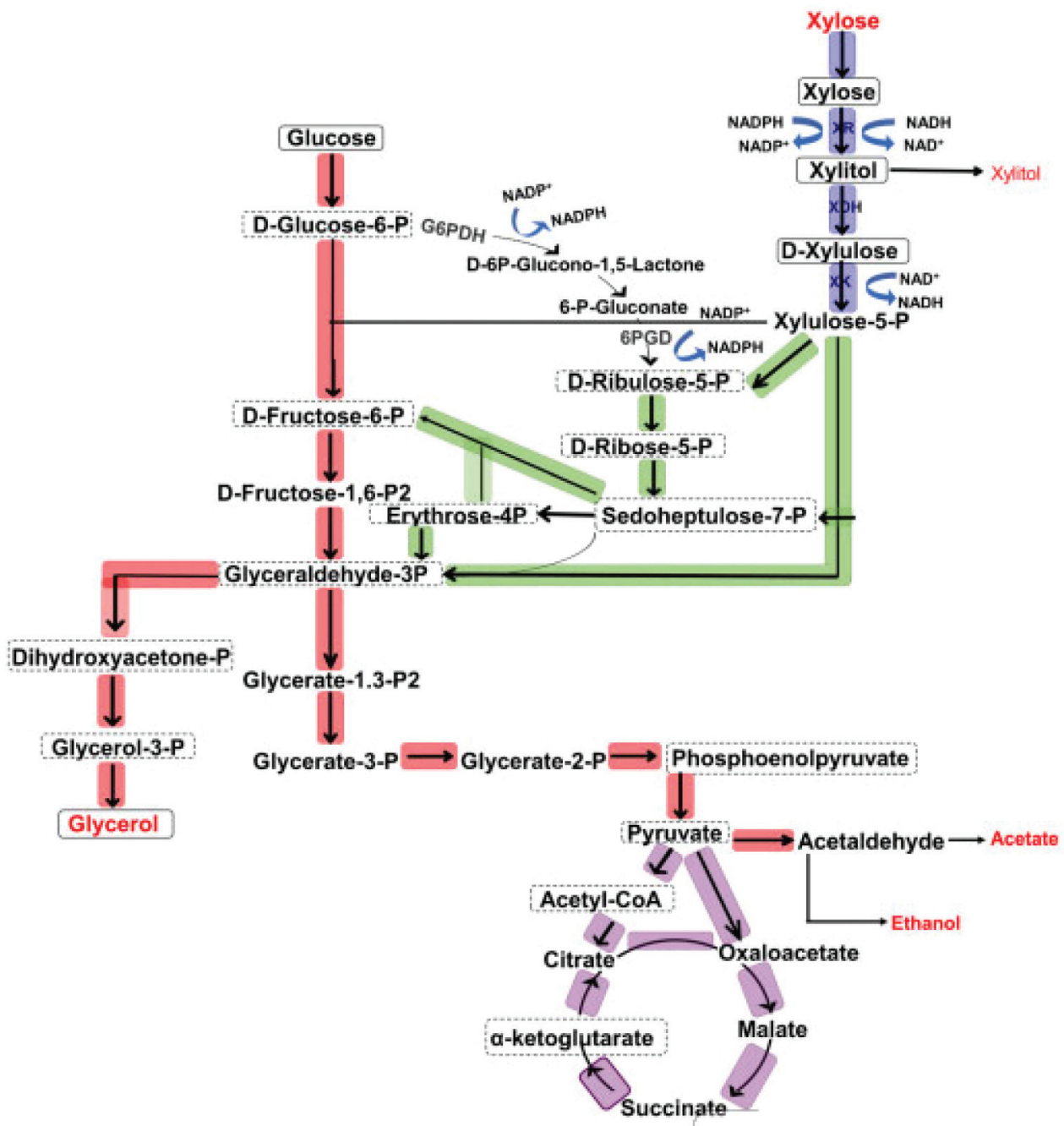

Figure 1. Simplified schematic of central carbon metabolism from xylose to ethanol by yeast ${ }^{11}$

$\mathrm{pH}$ adjusted to 4.0.12 This medium was used for growthing yeast S. meliponinorum FRP.09.

\section{Culture medium for fermentation}

Semi-synthetic medium $\left(\mathrm{g} \mathrm{L}^{-1}\right)$ : 0.5 of $\mathrm{MgSO}_{4} ; 1$ of $\mathrm{KH}_{2} \mathrm{P}_{4} ; 0.1$ of $\mathrm{NaCl} ; 0.1$ of $\mathrm{CaCl}_{2} ; 2.0$ of $\left(\mathrm{NH}_{4}\right)_{2} \mathrm{SO}_{4} ; 10$ of yeast extract and trace elements. Compounds in $\mathrm{mg} \mathrm{L}^{-1}$ : 0.5 of $\mathrm{H}_{3} \mathrm{BO}_{3} ; 0.04$ of $\mathrm{CuSO}_{4} ; 0.1$ of $\mathrm{FeCl}_{3} ; 0.4$ of $\mathrm{Na}_{2} \mathrm{MoO}_{4} ; 0.2$ of $\mathrm{ZnSO}_{4} ; 0.4$ of $\mathrm{MnSO}_{4}$; adjusted to $\mathrm{pH}$ 4. Xylose were included, separately, in the basic formulation, as the carbon source, at a concentration of $60 \mathrm{~g} \mathrm{~L}^{-1}$.

\section{Inoculum standardization for fermentation flask and bioreactor}

The standardization was done using the number of viable cells per milliliter in a Neubauer counting chamber using methylene blue and sodium citrate dye. ${ }^{13}$ The concentration of inoculum was established at approximately $1.0 \times 10^{8}$ cells $\mathrm{mL}^{-1}$.

The influence of agitation and aeration in xylose consumption kinetics and production of xylitol/ethanol by $S$. meliponinorum FRP.09

To assess the effects of agitation on xylose consumption kinetics, growth, cell viability and production of xylitol/ethanol by
S. meliponinorum FRP.09, the yeasts were pre-cultivated in a YEPD culture in $125 \mathrm{~mL}$ Erlenmeyer flasks, at $28^{\circ} \mathrm{C}$ (the temperature and $\mathrm{pH}$ were previously established as optimal for this strain - data not shown) and agitation of $150 \mathrm{rpm}$ for 24 to 48 hours. Aliquots were centrifuged at $10.000 \times \mathrm{g}$ for 15 minutes. The supernatant was discarded, and the pellet was used as inoculum to give a final cell concentration of $1.0 \times 10^{8}$ cell $\mathrm{mL}^{-1}$.

\section{Fermentation in flasks $(13.7 \%$ culture volume)}

Erlenmeyer flasks of $125 \mathrm{~mL}$ were sealed with fermentation valve. Sodium metabisulfite solution at $1 \mathrm{mg} \mathrm{mL}^{-1}$ was added to allow the release of $\mathrm{CO}_{2}$ and prevent the entrance of $\mathrm{O}_{2}$. The flasks containing $15 \mathrm{~mL}$ of the semi-synthetic medium described above, with initial $\mathrm{pH} 4.0$, were inoculated with sufficient pre-culture supernatant to give a final cell concentration of $1.0 \times 10^{8}$ cells $\mathrm{mL}^{-1}$. The flasks were incubated without any agitation, and also at 150 and $200 \mathrm{rpm}$ (no airflow). Samples were taken after 96 hours and the fermentation parameters evaluated were: xylose consumption; cell growth and viability, and also ethanol and xylitol production.

\section{Fermentation in a bioreactor}

The bioreactor (Cellingen 310 New Brunswick) has capacity for 4 liters and is equipped with temperature, agitation, aeration and $\mathrm{pH}$ controller. It was adjusted to $28{ }^{\circ} \mathrm{C}$ and $\mathrm{pH} 4.0$. The 
medium oxygenation was controlled by agitation and airflow: $0.1 \mathrm{vvm} / 100 \mathrm{rpm}, 0.2 \mathrm{vvm} / 150 \mathrm{rpm}, 0.5 \mathrm{vvm} / 200 \mathrm{rpm}$.

The inoculum was previously prepared in 2 liter flask containing 1 liter of YEPD culture medium ( $2 \%$ xylose) from a $250 \mathrm{~mL}$ suspension of cells that had been pre-cultured for 24 hours. The culture was incubated at $28^{\circ} \mathrm{C}$ for 48 hours at $200 \mathrm{rpm}$ (the previously established ideal rotation). After this period, aliquots were centrifuged at $10.000 \times \mathrm{g}$ for 15 minutes, the supernatant was discarded and the cells were resuspended in $200 \mathrm{~mL}$ of semisynthetic culture medium. This cell suspension was inoculated into the bioreactor fermentation vat containing $1.9 \mathrm{~L}$ of culture medium to reach a final volume of $2.1 \mathrm{~L}$. The fermentation proceeded for 96 hours and aliquots were removed every 24 hours for evaluation of growth, cell viability, and ethanol and xylitol production.

\section{Cell biomass and viability}

The concentration of cell biomass was determined using a spectrophotometer at $600 \mathrm{~nm}$ from a calibration curve showing the optical density of the dry weight cell concentration in $\mathrm{g} \mathrm{L}^{-1}$. The determination cell viability was determined using the vital staining with methylene blue method described by Lee et al. ${ }^{13} \mathrm{~A}$ solution was prepared containing a sample and methylene blue (1:1). This solution was homogenized and after 10 minutes, the colorless cells were counted in a Neubauer counting chamber.

\section{Ethanol quantification}

The ethanol was quantified using a gas chromatograph with a flame ionization detector (GC-FID Clarus 480). The analysis was carried out in an Elite-Wax capillary column (polyethylene glycol $0.25 \mathrm{~mm} \times 30 \mathrm{~m}$ x $0.15 \mathrm{~mm}$ ) with a slipt mode (1:20) using nitrogen as the carrier gas at a flow rate of $1 \mathrm{~mL} \mathrm{~min}^{-1}$. The injection and detection temperatures were the same at $250{ }^{\circ} \mathrm{C}$. A volume of $6 \mathrm{~mL}$ of sample was packaged in penicillin tubes sealed with a rubber septum and kept at $40{ }^{\circ} \mathrm{C}$ for 10 minutes. $200 \mu \mathrm{L}$ of the vapor phase was collected using a gas-tight syringe and injected into the chromatograph. Quantitation was determined using the calibration curve from 0.02 to $4 \%$ of aqueous ethanol.

\section{Quantification of xylose and xylitol}

The quantification of xylose and xylitol was carried out by High Performance Anion-Exchange Chromatography with Pulsed Amperometric Detection (HPAEC-PAD). All samples were centrifuged at $10000 \times \mathrm{g}$, filtered through a 0.22 -micron Whatman membrane, diluted and placed into $5 \mathrm{~mL}$ vials. $10 \mu \mathrm{L}$ was injected into the HPAEC-PAD system (Dionex ICS SP 5000) equipped with a CarboPac PA1 column. An isocratic run was performed with $500 \mathrm{mmol} \mathrm{L}^{-1}$ of $\mathrm{NaOH}$ at a flow rate of $1 \mathrm{~mL} \mathrm{~min}^{-1}$ and $25^{\circ} \mathrm{C}$. The eluents were prepared using ultrapure deionized water $(18 \mathrm{M} \Omega \mathrm{cm})$ and degasified using an ultrasonic bath. Data were collected and analyzed using Chromeleon software, version 6.8 (Dionex ICS $5000 \mathrm{SP})$.

\section{Process efficiency}

Ethanol and xylitol yield $(Y \mathrm{p} / \mathrm{s})$ : The conversion factor, which expresses the mass of ethanol produced per unit mass of xylose consumed, in grams, was calculated by equation 1 :

$$
y \frac{P}{s}=\frac{P}{\Delta s}=\frac{P}{S i-S f}
$$

P: final ethanol/xylitol concentration $\left(\mathrm{g} \mathrm{L}^{-1}\right)$; Si: initial concentrations of xylose present in the medium $\left(\mathrm{g} \mathrm{L}^{-1}\right)$; Sf: final concentrations of xylose present in the medium $\left(\mathrm{g} \mathrm{L}^{-1}\right)$.

Ethanol and xylitol volumetric productivity $(Q p)$ : The volumetric ethanol productivity was expressed as the amount of ethanol produced $\left(\mathrm{g} \mathrm{L}^{-1}\right)$ per hour, and it was calculated according to the equation 2:

$$
Q p=\frac{P}{T}
$$

P: final ethanol/xylitol concentration $\left(\mathrm{g} \mathrm{L}^{-1}\right)$; $\mathrm{T}$ : time of fermentation.

Conversion factor of xylose in cell mass $(Y x / s)$ : This parameter expresses the cell mass (g. cel) produced by consumed xylose mass (g), and was calculated according to equation 3:

$$
y \frac{x}{s}=\frac{\Delta x}{\Delta s}=\frac{X f-X i}{S i-S f}
$$

Si: initial concentrations of xylose $\left(\mathrm{g} \mathrm{L}^{-1}\right)$; Sf: final concentrations of xylose $\left(\mathrm{g} \mathrm{L}^{-1}\right)$; Xi: initial concentration of cell mass $\left(\mathrm{g} \mathrm{L}^{-1}\right)$; Xf: final concentration of cell mass $\left(\mathrm{g} \mathrm{L}^{-1}\right)$.

Conversion efficiency ( $\eta$ ) of ethanol: This fermentation parameter, expressed as a percentage, is the ratio between the experimental yield (Y p/s) and the theoretical yield (YT) of $0.511 \mathrm{~g} \mathrm{~g}^{-1}$ of glucose and/or xylose consumed (Ingledew, 1987) (Equation 4).

$$
\eta=\frac{Y p / s}{0.511} \times 100
$$

Conversion efficiency ( $\eta$ ) of xylitol: This fermentation parameter, expressed as a percentage, is the ratio between the experimental yield (Y p/s) and the theoretical yield (YT) of $0.905 \mathrm{~g} \mathrm{~g}^{-1}$ calculated by Barbosa et al. (1988), (Equation 5).

$$
\eta=\frac{Y p / s}{0.905} \times 100
$$

\section{Statistical analysis}

Analysis of variance was used to determine the significance of differences between conditions analyzed. The analysis was evaluated using Tukey's test at the 5\% level of significance. All statistical analyses were performed using the SISVAR software, UFLA. The graphics were obtained by Oringin Pro 8.5.1 software from the University of Oxford.

\section{RESULTS AND DISCUSSION}

\section{Erlenmeyer flask fermentation}

Among the evaluated conditions, it was observed that agitation at $200 \mathrm{rpm}$ promoted cell growth of S. meliponinorum FRP.09 achieving $1.9 \times 10^{8}$ cells in 96 hours, while in the static fermentation it showed no growth (Figure 2a). Absence or low concentration of oxygen dissolved in the medium can result in a stress of the microorganism ${ }^{12}$ contributing to a reduction in the cell viability. The static experiment also resulted in the settling of cells, making access to the nutrients difficult. Under agitation, the xylose consumption rate was much higher but there was a wider range of carbon source to produce ethanol and xylitol, reducing the growth yield. The yeast had significantly different xylose consumption rates in the 
three different sets of conditions evaluated, achieving the highest consumption rate of $67 \%$ at $200 \mathrm{rpm}$. There was no statistical difference in the xylitol and ethanol produced in the agitations at 150 and $200 \mathrm{rpm}$. None of the agitation levels significantly influenced
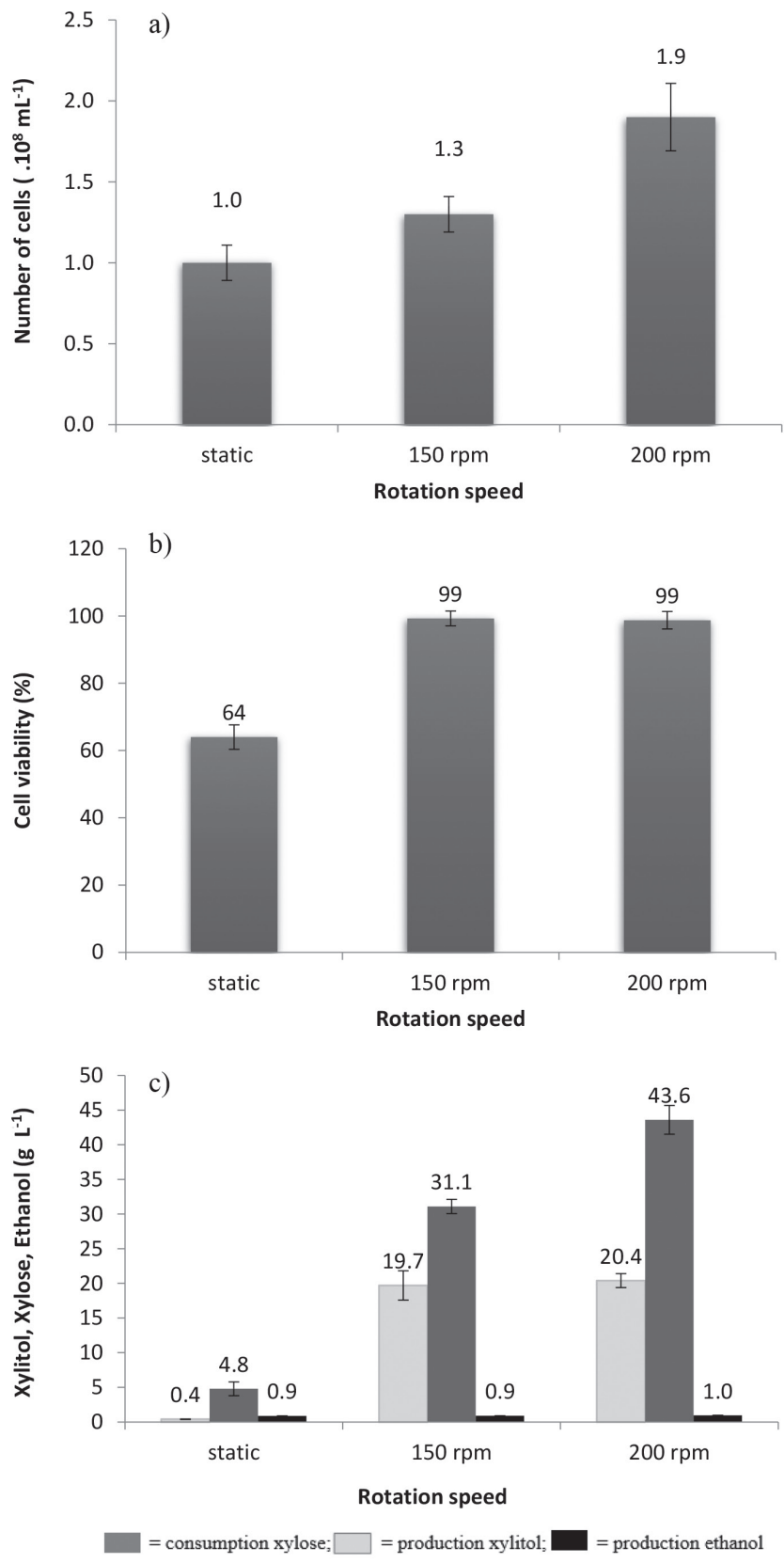

Figure 2. a) Quantification of number of cells, b) cell viability; and c) consumption and production by S. Meliponinorum FRP.09 in static and agitated (150 and 200 rpm) flask fermentation Media of three repetitions the production of xylitol. The increased agitation contributed to a better consumption of xylose with a respective increase in biomass production (Figure $2 \mathrm{c}, \mathrm{a}$ ).

The agitation at $150 \mathrm{rpm}$ favored the xylitol yield (Y p/s), providing a fermentation efficiency $(\eta)$ of $63 \%$ of the theoretical yield (Table 1). There was no statistical difference in volumetric productivity $(\mathrm{Qp})$ of ethanol under the three conditions evaluated. The volumetric productivity (Qp) of xylitol (Table) was slower when the fermentation was conduct-ed without agitation, which may primarily be due to the low number of viable cells (Figure 2b).

Kalhorinia et al. ${ }^{14}$ evaluated the production of ethanol by the yeast Candida intermedia MTCC 1404 in static conditions and agitation at $100-250 \mathrm{rpm}$ finding the best ethanol yield $\left(0.36 \mathrm{~g} \mathrm{~g}^{-1}\right)$ with agitation at $150 \mathrm{rpm}$ at 96 hours. Cheng et al. ${ }^{15}$ evaluated ethanol and xylitol production by the yeast Candida tropicalis W103 in hydrolyzed acid corn cob under two sets of conditions: $100 \mathrm{rpm}$ with $200 \mathrm{~mL}$ of medium in $500 \mathrm{~mL}$ flasks and $160 \mathrm{rpm}$ with $100 \mathrm{~mL}$ of medium in flasks same volume. Under the first set of conditions, there was an output of $7 \mathrm{~g} \mathrm{~L}^{-1}$ of xylitol and $25.3 \mathrm{~g} \mathrm{~L}^{-1}$ of ethanol. It was found that increasing the speed and decreasing the volume of medium in the flask increased the production of xylitol $\left(17.1 \mathrm{~g} \mathrm{~L}^{-1}\right)$ and decreased the ethanol $\left(9 \mathrm{~g} \mathrm{~L}^{-1}\right)$.

\section{Fermentation in a bioreactor}

In the experiments performed with S. meliponinorum FRP.09 in Erlenmeyer flasks, different values of the xylose consumption and cell growth were observed for different levels of agitation. So, the bioreactor experiments were performed in order to evaluate the xylose consumption, xylitol and ethanol production, cell growth and cell viability under controlled conditions of aeration of $0.1 / 100 ; 0.25 / 150$; $0.5 / 200 \mathrm{vvm} / \mathrm{rpm}$. The results for these parameters are shown in Figure 3. Figure 4 shows the results of xylitol yield (Y p/s) and growth $(\mathrm{Y} x / \mathrm{s})$, volumetric productivity (Qp) and conversion efficiency $(\eta)$.

Different airflows and agitation influenced the xylose consumption rate and the amount of xylitol produced. The results indicate that the more oxygen available in the medium, the higher the consumption of xylose and production of xylitol by S. meliponinorum FRP.09. An increase of $98 \%$ in xylose consumption was observed when the air flow and speed was increased from $0.1 \mathrm{vvm} / 100 \mathrm{rpm}$ to $0.25 \mathrm{vvm} / 150 \mathrm{rpm}$, and there was an increase of $123 \%$ in consumption when they were increased from $0.25 \mathrm{vvm} / 150 \mathrm{rpm}$ to $0.5 \mathrm{vvm} / 200 \mathrm{rpm}$ (Figure 3).

Oxygen is required for the transportation of some disaccharides ${ }^{16}$ and is also used in the production of sterols, unsaturated fatty acids and nicotinic acids, which are required for certain functions such as sugar transport through a membrane. ${ }^{17}$ Skoog and Hahn-Hãgerdal ${ }^{18}$ in a study of the oxygen requirement in the transport of xylose into the cell, noted that the uptake rate under aerobic conditions was higher when compared to cultures in anaerobic conditions, indicating that oxygen induces or activates the transport system.

In the same way as the experiments in flasks, different levels of agitation in experiments using the bioreactor had no effect on the

Table 1. Fermentation parameters of ethanol and xylitol by S. meliponinorum FRP.09 in static and agitated (150 and 200 rpm) flask fermentation: ethanol and xylitol yield; volumetric productivity of ethanol and xylitol; Fermentation efficiency of ethanol and xylitol ( $\eta$ )

\begin{tabular}{ccccccc}
\hline & \multicolumn{5}{c}{ Starmerella meliponinorum FRP.09 } \\
\hline $\begin{array}{c}\text { Rotation speed } \\
(\mathrm{rpm})\end{array}$ & Yield ethanol & Yield xylitol & Productivity ethanol & Productivity xylitol & $\begin{array}{c}\text { Fermentation } \\
\text { efficiency Ethanol (\%) }\end{array}$ & $\begin{array}{c}\text { Fermentation } \\
\text { efficiency xylitol }(\%)\end{array}$ \\
\hline static & 0.18 & 0.08 & 0.01 & 0.00 & 35.9 & 5.2 \\
150 & 0.03 & 0.63 & 0.01 & 0.21 & 5.6 & 63.0 \\
200 & 0.02 & 0.47 & 0.01 & 0.21 & 4.3 & 51.7 \\
\hline
\end{tabular}



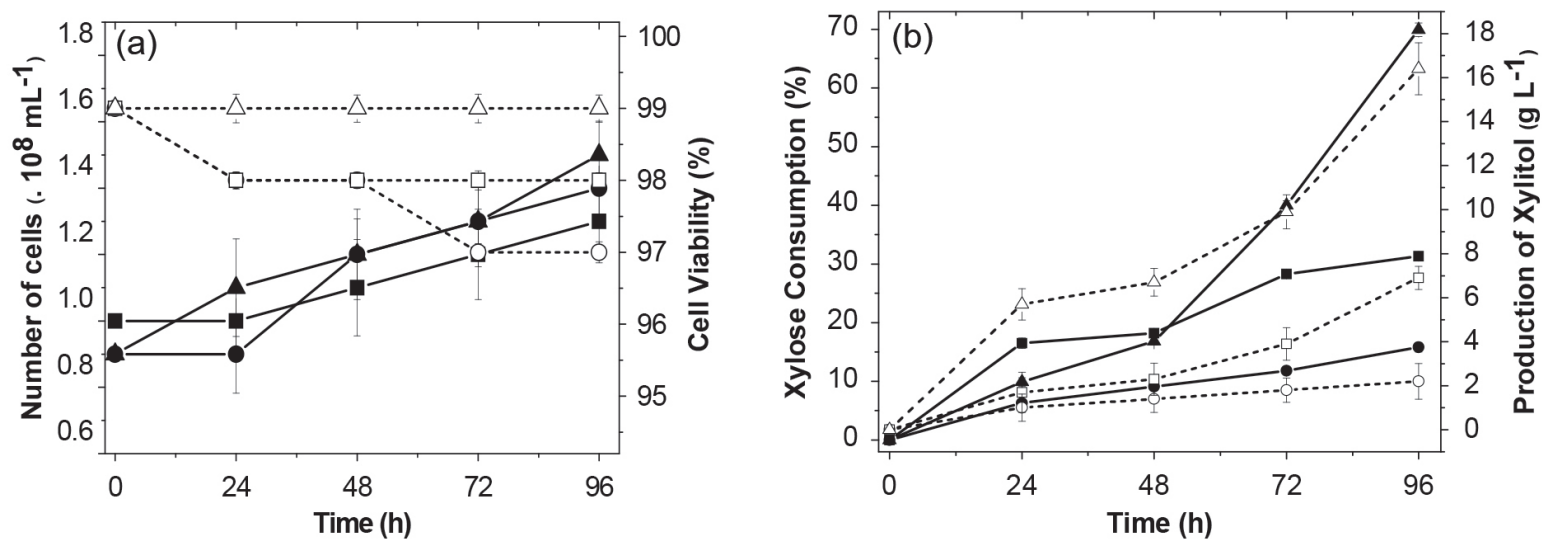

Figure 3. Metabolic responses to bioreactor fermentation for 96 hours with the yeast S. meliponinorum FRP.09 in culture medium with $70 \mathrm{~g} \mathrm{~L}^{-1} x y l o s e, p H$ $4.0,28{ }^{\circ} \mathrm{C}$, with an initial inoculum of $1.0 \times 10^{8} \mathrm{cell} \mathrm{mL}^{-1}$. (a) $=$ xylose consumption $0.12 \mathrm{vvm}, \mathbf{\square}=$ xylose consumption $0.25 \mathrm{vvm}, \boldsymbol{\Delta}=x y l o s e$ consumption $0.5 \mathrm{vvm}, \bigcirc=$ xylitol production $0.12 \mathrm{vvm}, \square=$ xylitol production $0.25 \mathrm{vvm}, \triangle=$ xylitol production $0.5 \mathrm{vvm} ; b)=$ number of cells $0.12 \mathrm{vvm}, \mathbf{\square}=$ number of cells $0.25 \mathrm{vvm}, \boldsymbol{\Delta}=$ number of cells $0.5 \mathrm{vvm}, \bigcirc=$ cell viability $0.12 \mathrm{vvm}, \square=$ cell viability $0.25 \mathrm{vvm}, \triangle=$ cell viability $0.5 \mathrm{vvm}$. Media of three repetitions

cell viability of $S$. meliponinorum FRP.09 yeast, that maintained a viability between 97 and $99 \%$ after 96 hours.

The significant increase in xylose consumption, with the increase of air flow, resulted in a higher yield growth $\left(0.2 \mathrm{~g} \mathrm{~g}^{-1}\right)$ in the lower flow $(0.1 \mathrm{vvm} / 100 \mathrm{rpm})$, without significantly increasing the number of cells.
In the experiments in the bioreactor, the increased airflow and rotation increased the xylitol production with no ethanol formation by S. meliponinorum FRP.09 (Figure 4). This indicates that a smaller volume of air $(0.1 \mathrm{vvm} / 100 \mathrm{rpm})$ is sufficient to inhibit ethanol production by this strain. However, different organisms respond differently to oxygen. Ethanol production was assessed by Pichia

\section{$0.1 \mathrm{vvm} / 100 \mathrm{rpm}$}

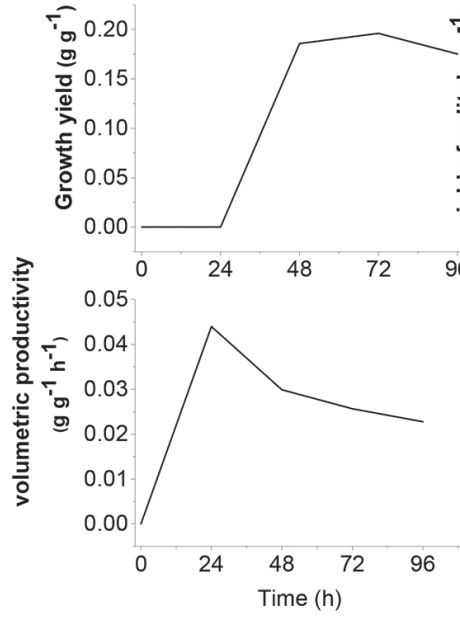

\section{$0.25 \mathrm{vvm} / 150 \mathrm{rpm}$}
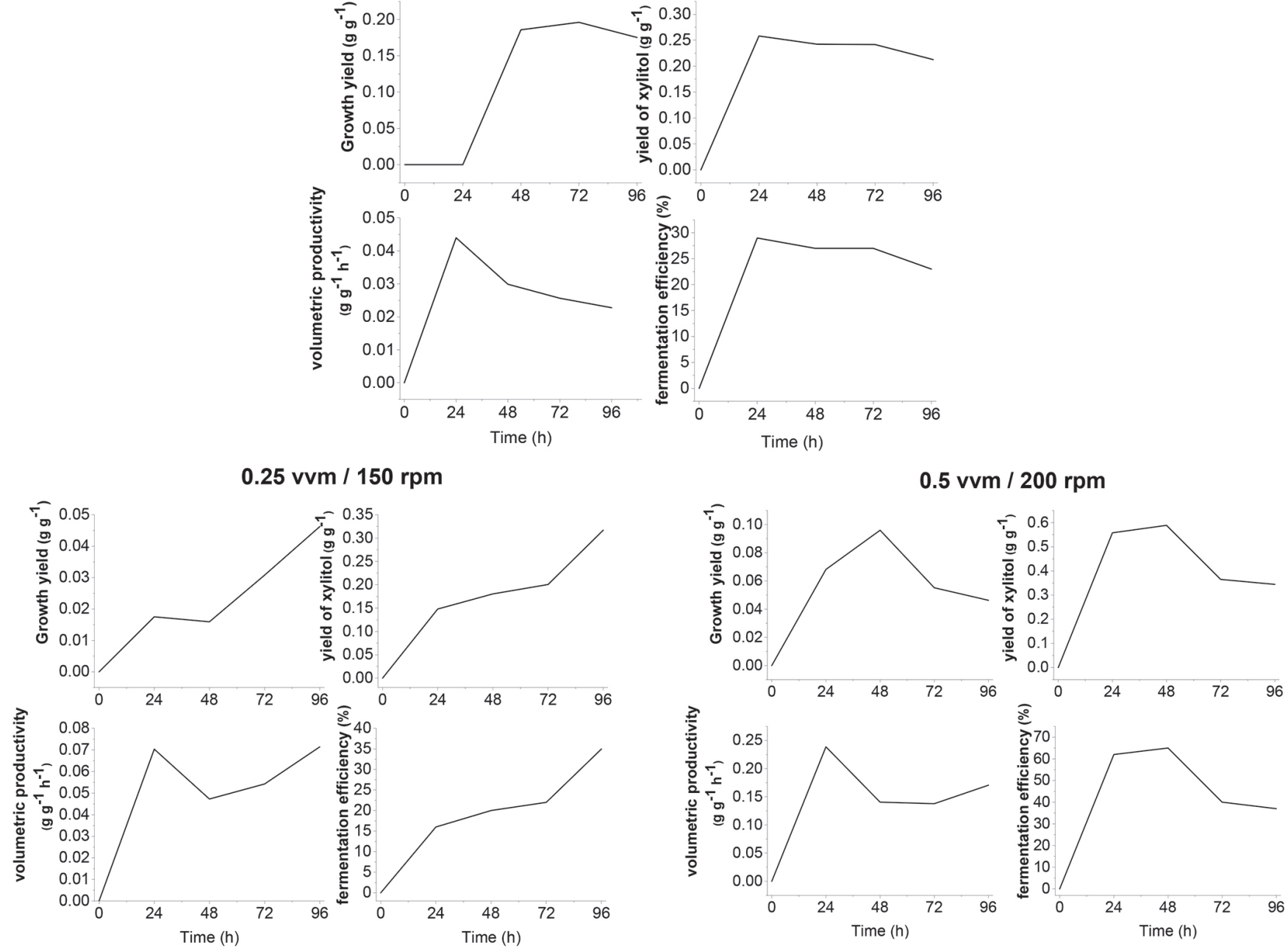

Figure 4. Xylitol yield $(Y \mathrm{p} / \mathrm{s})$ and growth $(Y x / \mathrm{s})$, xylitol volumetric productivity $(Q p)$ and conversion efficiency ( $\eta)$ in bioreactor fermentation using semisynthetic medium with a concentration of $70 \mathrm{~g} \mathrm{~L}{ }^{-1} x y l o s e$, for 96 hours, at a controlled temperature of $28{ }^{\circ} \mathrm{C}$ and a $\mathrm{pH}$ of 4.0 
stipitis ${ }^{19}$ in an agitated tank bioreactor using a semisynthetic medium containing xylose $\left(90.0 \mathrm{~g} \mathrm{~L}^{-1}\right)$ as a carbon source. Experimental tests were conducted to evaluate the influence of aeration $(0.25$ to $0.75 \mathrm{vvm}$ ) and agitation (150 to $250 \mathrm{rpm}$ ) in ethanol production. The results showed that increased agitation and decreased aeration favored the production of ethanol, which was maximal (26.7 $\left.\mathrm{g} \mathrm{L}^{-1}\right)$ using $250 \mathrm{rpm}$ and $0.25 \mathrm{vvm}$. Under these conditions, the ethanol yield and productivity, and process efficiency was $0.32 \mathrm{~g} \mathrm{~g}^{-1}, 0.32 \mathrm{~g} \mathrm{~L}^{-1} \mathrm{~h}^{-1}$ and $63 \%$, respectively. Veras et al., ${ }^{5}$ making a comparative assessment of the four-native xylose-consuming yeasts showed that the S. stipitis and $S$. passalidarum strains presented the highest potential for ethanol production from xylose. Both yeast strains showed similar ethanol yields near theoretical under oxygen-limited condition. Besides, S. passalidarum presented the highest xylose consumption and ethanol production under anaerobiosis. The highest performing yeasts, i.e. with higher xylose consumption rate and higher concentration of ethanol, during fermentation anaerobic xylose showed higher ratio of NADH/NADPH XR activity. Authors also found higher values of xylitol $\left(15.4 \mathrm{~g} \mathrm{~L}^{-1}\right)$ for the yeasts Candida tenuis under conditions of limited oxygenation, while in aerobic conditions they observed a reduction $\left(8.0 \mathrm{~g} \mathrm{~L}^{-1}\right)$ in the production values.

In this study, the yeast $S$. meliponinorum FRP.09 achieved the best xylitol yield of $0.6 \mathrm{~g} \mathrm{~g}^{-1}$, when the fermentation was conducted with an air flow/rotation speed of $0.5 \mathrm{vvm} / 200 \mathrm{rpm}$, resulting in a conversion efficiency of $63 \%$ of the theoretical yield (Figure 4). The best volumetric productivity was also achieved under these conditions, reaching $0.24 \mathrm{~g} \mathrm{~L}^{-1} \mathrm{~h}^{-1}$. The best results in performance, productivity and efficiency found in a bioreactor did not differ from the best results achieved in the experiments done in flasks at $150 \mathrm{rpm}$.

Depending on the availability of oxygen, xylose can be directed to the production of xylitol, biomass growth, or respiration. To obtain a high yield of xylitol, the flow of xylose to xylulose must be controlled by providing sufficient oxygen for the regeneration of NADPH, and maintenance of the cells. Low levels of oxygen favor the production of xylitol, decrease the NAD+/NADH ratio, favor the reaction catalyzed by xylitol dehydrogenase and also favor the accumulation of xylitol by changing the equilibrium constant. ${ }^{20}$ Complete aeration is also detrimental to the production of xylitol as proved in earlier studies. ${ }^{21}$

Baz, Shetaia and Elkhouli ${ }^{20}$ evaluated the effects of aeration and rotation in the production of xylitol from D-xylose by the yeast Candida tropicalis (AY 2007), using a semisynthetic medium. They observed that xylitol production $\left(36 \mathrm{~g} \mathrm{~L}^{-1}\right.$ in $59 \mathrm{~h}$ ) was favored by oxygen-limited conditions, using an air flow of $0.3 \mathrm{vvm}$ and rotation of $200 \mathrm{rpm}$. When the conditions were an air flow of $1.5 \mathrm{vvm}$ and rotation of $500 \mathrm{rpm}$, the yeast production reached only $30.9 \mathrm{~g} \mathrm{~L}^{-1}$ of xylitol after $66 \mathrm{~h}$, but the yield and conversion efficiency were the same ( $\mathrm{Y} / \mathrm{s}=0.70 \mathrm{~g}^{-1}$ and $\eta=77 \%$ ) for both sets of conditions.

\section{CONCLUSIONS}

From the results, it can be concluded that the $S$. meliponinorum FRP.09 shows potential for the production of xylitol, reaching a yield of $0.6 \mathrm{~g}$ of xylitol per $\mathrm{g}$ of xylose consumed. This yield results in a conversion efficiency of $63 \%$ of the theoretical yield. This strain has its viability reduced in anaerobic conditions and stops the production of ethanol while increasing the production of xylitol when the concentration of oxygen and agitation are increased.

\section{REFERENCES}

1. Huang, C. F.; Jiang, Y. F.; Guo, G. L.; Hwang, W. S.; Bioresour. Technol. 2011, 102, 3322.

2. Yewale, T.; Panchwagh, S.; Sawale, S.; Jain, R.; Dhamole, P. B.; 3 Biotech 2017, 7, 68.

3. Dasgupta, D.; Bandhu, S.; Adhikari, D. K.; Ghosh, D.; Microbiol. Res. 2017, 197, 9 .

4. Hammond, J. R. M. In The Yeast: Yeast Technology; Rose, A. H.; Harrison, J. S., eds.; Academic Press: New York, 1987, cap. 2.

5. Veras, H. C. T.; Parachin, N. S.; Almeida, J. R. M.; Microb. Cell Fact. 2017, 16, 153.

6. Diz, J.; Cruz, J. M.; Domínguez, H.; Parajó, J.; Food Technol. Biotechnol. 2002, 40, 191.

7. Mayerhoff, Z.; Roberto, I.; Silva, S.; Braz. J. Chem. Eng. 1997, 28, 151.

8. Converti, A.; Perego, P.; Dominguez, J. M.; Appl. Biochem. Biotechnol. 1999, 82, 141.

9. Canilha, L.; Carvalho, W.; Almeida, F. M.; de Almeida e Silva, J.; Braz. J. Microbiol. 2008, 39, 333.

10. Dominguez, J. M.; Cao, N. J.; Krishnan, M. S.; Gong, C. S.; Tsao, G. T.; Biotechnol. Tech. 1997, 11, 339.

11. Campos, C. G.; Veras, H. C. T.; Ribeiro, J. A. de A.; Costa, P.; Araujo, K. P.; Rodrigues, C. M.; Abdelnur, P. V.; J. Am. Soc. Mass Spectrom. 2017, 12,2646

12. White, C.; Zainasheff, J.; Yeast: The Practical Guide to Beer Fermentation, Brewers Publications: Boulder, 2010.

13. Lee, S. S.; Robinson, F. M.; Wang, H. Y.; Biotechnol. Bioeng. Symp. 1981, 11, 641.

14. Kalhorinia, S.; Goli, J. K.; Rao, L. V.; Biosci., Biotech. Res. Asia 2014, 11,641 .

15. Cheng, K. K.; Wu, J.; Lin, Z. N.; Zhang, J. A.; Biotechnol. Biofuels 2014, 7, 166.

16. Sims, A. P.; Barnett, J. A.; J. Gen. Microbiol. 1978, 106, 277.

17. Skoog, K.; Hahn-Hãgerdal, B.; Enzym. Microbial Technol. 1988, 10, 66.

18. Skoog, K.; Hahn-Hãgerdal, B.; Appl. Environ. Microbiol. 1990, 56, 3389.

19. Silva, J. P. A.; Mussatto, S. I.; Roberto, I. C.; Teixeira, J. A.; Braz. J. Chem. Eng. 2011, 28, 151.

20. Baz, A. F. E. 1.; Shetaia, Y. M.; Elkhouli, R. R.; Afr. J. Biotechnol. 2011, 10, 15353.

21. Faria, L. F.; Gimenes, M. A.; Nobrego, R.; Pereira, N.; Appl. Biochem. Biotechnol. 2002, 100, 449. 